\title{
Characterization of enterotoxin A-producing Staphylococcus aureus
}

This article was published in the following Dove Press journal: Infection and Drug Resistance

\author{
Dong Chen ${ }^{1, *}$ \\ Qifa Song ${ }^{2, *}$ \\ Zhaojun $\mathrm{Xu}^{3}$ \\ Dandan Zhang ${ }^{2}$
}

'Department of Clinical Laboratory, Sixth People's Hospital of Wenzhou, Wenzhou, Zhejiang Province, People's Republic of China; ${ }^{2}$ Department of Microbiology, Ningbo Municipal Center for Disease Control and Prevention, Ningbo, Zhejiang Province, People's Republic of China; 'Intensive Care Unit, Ningbo No. 2 Hospital, Zhejiang, People's Republic of China

*These authors contributed equally to this work
Correspondence: Dandan Zhang No. 237, Yongfeng Road, Ningbo, Zhejiang Province 315010, People's Republic of China

Tel +8657487206950

Email Zhangdd@nbcdc.org.cn
Purpose: This study aims to characterize the wild-type staphylococcal enterotoxin A (SEA)producing Staphylococcus aureus.

Materials and methods: We identified 29 wild-type sea-positive $S$. aureus isolates from dairy and meat samples, as well as from patients, measured the amount of SEA produced under favorable cultivation conditions using enzyme-linked immunosorbent assay and sea mRNA transcriptional level and investigated the phage type as well as genetic diversity by means of pulsed-field gel electrophoresis and multilocus sequence typing.

Results: Among 29 sea-positive isolates, 22 were from food sources (including one outbreak case) and seven from clinical patients. Five enterotoxin gene profiles, namely, sea (14 isolates), sea $+\sec (9$ isolates), sea+seb (4 isolates), sea+seb+sec (1 isolate) and sea+seb+sed (1 isolate), were identified. Multilocus sequence typing generated sequence type (ST)1 (13 isolates), ST6 (5 isolates), ST59 (3 isolates), ST239 (3 isolates), ST5 (2 isolates), ST188 (2 isolate) and ST15 (1 isolate). The amount of SEA per $10^{8}$ colony-forming unit (CFU) after $24 \mathrm{~h}$ of incubation was 1.1-33.5 (mean, 8.74; SD, 7.7) $\mathrm{ng} / 10^{8} \mathrm{CFU}$. The amount of SEA per hour incubation in the log growth phase was $0.1-12.0$ (mean, 2.37; SD, 3.06) ng/10 $\mathrm{CFU}$. Overall, $54.2 \%$ of SEA was produced in the log growth phase. Both the transcriptional level of sea mRNA and the amount of SEA in the log growth phase correlated well with the amount of SEA after $24 \mathrm{~h}$ of cultivation. Four isolates, namely, SA-212, SA-217, SA-340 and SA-341, were categorized to be of high SEA production (877-1,109 ng/mL, $24 \mathrm{~h})$. The total amount of SEA was mainly based on the amount of SEA in $10^{8} \mathrm{CFU}$, not the relatively fixed bacterial cell counts $\left(21.1-43 \times 10^{8} \mathrm{CFU} / \mathrm{mL}\right)$. Seven isolates from patients all carried the $\Phi \mathrm{Mu} 3 \mathrm{~A}$ phage, whereas 21 of the 22 isolates from the environmental sources all carried the $\Phi S a 3 m s$ phage. Conclusion: The present study exhibits varied SEA production capacity of the wild sea-positive S. aureus strains. An apparent boundary in phage types between strains from the clinical samples and strains from the environment was also identified.

Keywords: Staphylococcus aureus, staphylococcal enterotoxin A, multilocus sequence typing, phage, SEA production capacity

\section{Introduction}

Staphylococcal food poisoning (SFP) typically exhibits sudden onset of nausea, violent vomiting, abdominal cramps and sometimes diarrhea. It is one of the most common forms of bacterial foodborne outbreaks worldwide and has been reported to be the fourth most common type of foodborne outbreaks in Europe in $2011 .^{1}$ The major causative agents of SFP are staphylococcal enterotoxins (SEs). SEs are often produced in food contaminated with enterotoxin-producing Staphylococcus aureus (S. aureus) due to improper handling and storage. Classical SEs are classified into five types, namely, staphylococcal entero- 
toxin A (SEA), SEB, SEC, SED and SEE, by the serological method. Meanwhile, $23 \mathrm{SE}$ types are known, but it is not yet known how relevant some of these are for SFPs. ${ }^{2}$ Up to now, commercial assays only measure types A-E. The five classical SEs contribute to $95 \%$ of the SFP outbreaks. ${ }^{3}$ In particular, SEA is viewed to be most frequently associated with SFP and is detected in $>50 \%$ of relevant outbreaks. ${ }^{4,5}$ SEA is encoded by the sea gene existing on two types of phages. ${ }^{6}$ Previous studies have proved that the minimal toxic dose of SEA for humans ranges from 20 to $100 \mathrm{ng}$. $^{7,8}$

A number of experimental studies have been carried out to characterize the diverse SE gene profiles in strains from various food sources and have found that over a half of the $S$. aureus isolates from meat or milk are enterotoxigenic. ${ }^{9,10}$ Despite ubiquitous presence of $S$. aureus in the environment, whether an SFP will occur is determined largely by enterotoxin levels in contaminated food. However, studies exploring the differential enterotoxin production ability in wild-type $S$. aureus strains are scant. Only limited knowledge on impacts of temperature, lactic acid and processed pork meat in standard strains is available. ${ }^{11}$

To investigate the SEA production capacity of S. aureus isolates harboring the sea gene, we identified 29 wild-type sea-positive $S$. aureus isolates that were isolated from dairy and meat samples, as well as from patients, measured the amount of SEA produced in the log growth phase and after $24 \mathrm{~h}$ of incubation under favorable cultivation conditions using enzyme-linked immunosorbent assay (ELISA) and relevant transcriptional level of sea mRNA and investigated the phage types, as well as genetic diversity by means of pulsed-field gel electrophoresis (PFGE) and multilocus sequence typing (MLST).

\section{Materials and methods Staphylococcus aureus isolates}

The $S$. aureus isolates used in this study were recovered from SFP outbreaks, dairy and meat samples as well as from clinical samples as part of the routine hospital laboratory procedure. The isolates were identified using standard laboratory techniques including Gram stain, plasma coagulase test, biochemical reactions by the Vitek 2 Gram-positive identification card (bioMérieux, Marcy l'Etoile, France) and polymerase chain reaction (PCR) detection of the $n u c$ gene. ${ }^{12}$

\section{DNA extraction and PCR amplification}

Genomic DNA of $S$. aureus isolates was extracted using bacterial genomic DNA extraction kits (TaKaRa MiniBEST, Ver.3.0; TaKaRa, Kawasaki, Japan). The sea, seb, sec, sed and see genes were amplified according to the methodologies reported in a previous study. ${ }^{13}$ Staphylococcus aureus ATCC25923 and a sea-positive $S$. aureus proved by sequencing were used as a negative and a positive control for the sea gene, respectively. Isolates with the sea gene were used to determine the SEA production capacity.

\section{MLST and PFGE}

MLST was conducted on sea-positive $S$. aureus isolates by means of amplifying seven house-keeping genes ( $\operatorname{arc} C$, aroE, $g l p F, g m k, p t a, t p i$ and yqiL) listed on the S. aureus MLST website (http://saureus.mlst.net/). ${ }^{14}$ The allelic profile of a $S$. aureus isolate appearing as an array of seven allele numbers was derived by sequencing internal fragments of these seven house-keeping genes (Sangon Biotech Company, Shanghai, China). The sequence types (STs) were assigned on the basis of the array of seven allele numbers using the same website.

PFGE was conducted to investigate genetic relatedness of the sea-positive $S$. aureus isolates according to the PulseNet standardized protocol. ${ }^{15}$ All image patterns were normalized against the pattern of the Salmonella Braenderup H9812 reference standard. Image data were transferred into software BioNumerics 7.1 (Applied Maths, Sint-Martens-Latem, Belgium) and processed to identify clusters of isolates. Dendrograms of the PFGE patterns were constructed using the unweighted pair-group method.

\section{Culture conditions for the determination of SEA}

Favorable cultivation was done in brain heart infusion (BHI) broth or on $\mathrm{BHI}$ agar at $37^{\circ} \mathrm{C}$ as described previously with some modifications. ${ }^{11}$ S. aureus isolates with the sea gene were transferred from a stock to BHI agar for overnight incubation, and one colony was inoculated into $10 \mathrm{~mL}$ of broth for overnight culture prior to the experiment. Portions of $10 \mathrm{~mL}$ culture were inoculated into $50 \mathrm{~mL}$ of broth at a final cell concentration of $10^{5}$ colony-forming unit $(\mathrm{CFU}) / \mathrm{mL}$ and cultivated with shaking at $150 \mathrm{rpm}$. Culture was taken at $5 \mathrm{~h}$ of growth time from the $50 \mathrm{~mL}$ inoculated broth and used as a seed culture for the following assay. Then, the seed culture was inoculated into $50 \mathrm{~mL}$ of broth under the same conditions. In this way, we could ensure to obtain culture almost in the $\log$ growth phase of bacteria. Cultures were taken after $4 \mathrm{~h}, 6 \mathrm{~h}$ and $24 \mathrm{~h}$ of incubation to determine the SEA concentration. At $6 \mathrm{~h}$ cultivation, bacterial growth almost entered the stationary phase. Bacterial cells were counted by colony counting on plates after serial 10 -fold dilutions of the bacterial cultures and were expressed as $\mathrm{CFU} / \mathrm{mL}$. 


\section{ELISA for the determination of SEA}

The concentration of extracellular SEA was determined for the sea-positive isolates using Ridascreen SET A, B, C, D and E (R-Biopharm, Darmstadt, Germany) following the manufacturer's instructions. In short, $S$. aureus liquid cultures were centrifuged at $3,500 \times g$ at $10^{\circ} \mathrm{C}$ for $10 \mathrm{~min}$. The supernatant was diluted to $1: 100,1: 200$ and $1: 500(\mathrm{v} / \mathrm{v})$ with $0.85 \% \mathrm{NaCl}$ solution to ensure that the resulting values were within the detection limit of the ELISA kit. SEA standard $(0.1 \mathrm{ng} / \mathrm{mL}$; Toxin Technology Inc., Sarasota, FL, USA) and culture supernatants were added onto the plate $(100 \mu \mathrm{L} /$ well $)$ at appropriate dilutions. The optical density $\left(\mathrm{OD}_{405}\right)$ of each well was measured using a microplate reader (Multiskan Ascent, Thermo Electron Corporation, Waltham, MA, USA). $\mathrm{OD}_{405}$ values were plotted against SEA concentrations. SEA concentrations for each isolate were calculated from linear regression. Three replicate measurements were obtained to ensure the reliability of results.

\section{Transcriptional level of sea mRNA in the log growth phase}

The total RNA of culture in the log growth phase was extracted using TRIzol (Thermo Fisher Scientific, Waltham, MA, USA) according to the product manual. Pelleted RNA was resuspended in RNA storage solution (TaKaRa). RNA purity and concentration were verified by electrophoresis and $\mathrm{OD}_{260} / \mathrm{OD}_{280}$ absorption ratio $>1.95$ using a NanoDrop 2000 Spectrophotometer (Thermo Fisher Scientific). First-strand cDNA was synthesized from the suspended RNA extraction $(1 \mu \mathrm{g})$ in two separate reverse transcription assays using specific reverse primers for the sea gene and the 16S rRNA gene (Table 1). Real-time PCR amplification was conducted using quantitative PCR Direct SYBR Premix (TaKaRa) on Applied Biosystems 7500 Real-Time PCR System (Thermo Fisher Scientific). Each reaction contained $15 \mu \mathrm{L}$ of quantitative
PCR premix, $1 \mu \mathrm{L}$ of each primer $(c=10 \mu \mathrm{M}), 2 \mu \mathrm{L}$ of cDNA template and $11 \mu \mathrm{L}$ of water. The amplification conditions for sea and 16S rRNA genes were initial denaturation at $98^{\circ} \mathrm{C}$ for $1 \mathrm{~min}$, followed by 40 cycles of $95^{\circ} \mathrm{C}$ for $15 \mathrm{~s}, 60^{\circ} \mathrm{C}$ for $15 \mathrm{~s}$ and $72^{\circ} \mathrm{C}$ for $45 \mathrm{~s}$. The cycle threshold $(\mathrm{Ct})$ values for sea and 16S rRNA genes were determined. The relative sea expression was obtained by the $\Delta \mathrm{Ct}$ method for each isolate by comparing the sea $\mathrm{Ct}$ value to the $16 \mathrm{~S}$ rRNA Ct value. ${ }^{16}$ The relative expression ratio was calculated for each isolate. Three experimental replicates were performed for each reaction.

\section{Parameters for assessing the SEA production capacity}

To assess the capacity of SEA production, four parameters as previously described with some modifications, ${ }^{17} \mathrm{ie}$, total amount of SEA (ng/mL) and amount of SEA per $10^{8} \mathrm{CFU}$ (ng/10 ${ }^{8} \mathrm{CFU}$ ) after $24 \mathrm{~h}$ of incubation, amount of SEA per $10^{8} \mathrm{CFU}$ per hour and transcriptional level of sea mRNA in the log growth phase between $4 \mathrm{~h}$ and $6 \mathrm{~h}$ of incubation were determined to compare the SEA production ability between isolates. The amount of SEA per $10^{8} \mathrm{CFU}$ was calculated as follows: amount of SEA divided by bacterial count at the same time with unit of ng/ $10^{8} \mathrm{CFU}$. The amount of SEA per hour in the log growth phase was calculated as following: amount of SEA after $6 \mathrm{~h}$ of incubation minus that after $4 \mathrm{~h}$ of incubation, then divided by 2 . The mRNA expression ratio of sea gene was sea $\mathrm{Ct}$ value to $16 \mathrm{~S}$ rRNA Ct value as previously described. ${ }^{16}$

\section{Amplification of gene encoding prophage tail protein}

To determine two types of phages (referred to as $\Phi \mathrm{Mu} 3 \mathrm{~A}$ and $\Phi S a 3 \mathrm{~ms}$ ), we designed two sets of primers according to the highly varied regions of gene encoding phage tail protein, ie, from $1,120 \mathrm{bp}$ to the end of 1,385 bp-long gene of ФМu3A

Table I Primers used in this study

\begin{tabular}{|c|c|c|c|c|}
\hline Gene & Primers $\left(5^{\prime} \rightarrow 3^{\prime}\right)$ & Amplicon size (bp) & Accession number & References \\
\hline \multicolumn{5}{|c|}{ For genes encoding phage tail protein } \\
\hline \multirow[t]{2}{*}{ ФМu3А } & ФMU3A-I: GTAAATTCTTTGTGCAGCTTT & 325 & NC_009782 & This study \\
\hline & ФМU3A-2: TGAACAACAAAACAATTССТT & & & \\
\hline \multirow[t]{2}{*}{$\Phi$ Фa3ms } & ФSa3ms-I: CATCAAAGTATGCAAACCAAT & 307 & NC_002953 & This study \\
\hline & ФSa3ms-2: CAAATAGACAATAAAACCATTG & & & \\
\hline \multicolumn{5}{|c|}{ For SEA mRNA expression analysis } \\
\hline \multirow[t]{2}{*}{ sea } & sea-I: CCTTTGGAAACGGTTAAAACG & 127 & & 13 \\
\hline & sea-2: TCTGAACCTTCCCATGAAAAAC & & & \\
\hline \multirow[t]{2}{*}{ I6S rRNA } & I6sRNA-I: GTGTAGCGGTGAAATGC & 115 & & This study \\
\hline & I6sRNA-2: GTTTACGGCGTGGACTA & & & \\
\hline
\end{tabular}

Abbreviation: SEA, staphylococcal enterotoxin $A$. 
(accession no. NC_009782) and the end of 1,391 bp-long gene of $\Phi S a 3 m s$ (accession no. NC_002953). For each reaction of $50 \mu \mathrm{L}, 25 \mu \mathrm{L}$ of PCR Master Mix (Promega Corporation, WI, USA), $2 \mu \mathrm{L}$ of each primer $(c=10 \mu \mathrm{M})$, $2 \mu \mathrm{L}$ of DNA template and $21 \mu \mathrm{L}$ of water were added. PCR cycling conditions included the following: $5 \mathrm{~min}$ hot start at $95^{\circ} \mathrm{C}$, followed by 30 amplification cycles (denaturation at $95^{\circ} \mathrm{C}$ for $45 \mathrm{~s}$, annealing at each set of primer-specific annealing temperature for $45 \mathrm{~s}$ and elongation at $72^{\circ} \mathrm{C}$ for $45 \mathrm{~s}$ ), a final elongation step at $72^{\circ} \mathrm{C}$ for $10 \mathrm{~min}$ and a cooling step. Target-specific amplicons were confirmed by electrophoresis using a $1 \%$ agarose gel.

\section{Results}

A total of 29 wild-type $S$. aureus isolates with the sea gene were identified from $168 \mathrm{~S}$. aureus isolates. These sea-positive isolates comprised 22 from food sources (including one outbreak case) and seven from patient samples (Table 2). The following five SE profiles were identified in 29 isolates: sea (14 isolates), sea+sec (9 isolates), sea+seb (4 isolates), sea+seb+sec (1 isolate) and sea+seb+sed (1 isolate), revealing $55 \%$ of isolates having more than one of five classical SE genes.

Seven STs were identified in 29 isolates, including ST1 (13 isolates), ST6 (5 isolates), ST59 (3 isolates), ST239

Table 2 SEA production capability of 29 sea-positive Staphylococcus aureus in terms of amount of SEA per hour in the log growth phase and after $24 \mathrm{~h}$ of cultivation

\begin{tabular}{|c|c|c|c|c|c|c|c|c|c|c|}
\hline \multirow[t]{2}{*}{ Strains } & \multirow[t]{2}{*}{ ST } & \multirow{2}{*}{$\begin{array}{l}\text { SE } \\
\text { profile }\end{array}$} & \multirow[t]{2}{*}{ Source } & \multirow[t]{2}{*}{ Phage } & \multicolumn{2}{|c|}{ CFU $\left(\times 10^{8} / \mathrm{mL}\right)$} & \multicolumn{2}{|c|}{ SEA (ng/ $10^{8}$ CFU) } & \multirow{2}{*}{$\begin{array}{l}\text { Total SEA } \\
(\mathrm{ng} / \mathrm{mL}, \\
24 \mathrm{~h})\end{array}$} & \multirow{2}{*}{$\begin{array}{l}\text { Expression ratio } \\
\text { at the log growth } \\
\text { phase }\end{array}$} \\
\hline & & & & & $6 \mathrm{~h}$ & $24 \mathrm{~h}$ & $\begin{array}{l}\text { Per hour } \\
\text { at the log } \\
\text { growth } \\
\text { phase }\end{array}$ & $24 \mathrm{~h}$ & & \\
\hline SA-2 & STI88 & $A$ & Dairy & ФSa3ms & 16.2 & 33.2 & 0.1 & I.I & 36 & Baseline \\
\hline SA-16 & ST6 & A & Meat & $\Phi S a 3 m s$ & 21.1 & 36.1 & 2.1 & 11.2 & 404 & 3.2 \\
\hline SA-19 & STI88 & $A$ & Dairy & ФSa3ms & 19.0 & 37.0 & 0.6 & 2.1 & 77 & 3.1 \\
\hline SA-56 & ST6 & $A C$ & Meat & ФSa3ms & 18.1 & 34.6 & 1.5 & 5.9 & 204 & 5.6 \\
\hline SA-83 & ST6 & $A C$ & Meat & $\Phi \mathrm{Sa} 3 \mathrm{~ms}$ & 16.0 & 31.1 & 1.2 & 4.1 & 128 & 1.7 \\
\hline SA-112 & STI & $A C$ & Meat & $\Phi S a 3 m s$ & 31.1 & 43.0 & 3.1 & 8.3 & 357 & 1.0 \\
\hline SA-I48 & STI & $A B D$ & Meat (SFP) & ФSa3ms & 14.5 & 30.5 & 2.8 & 8.1 & 247 & 2.2 \\
\hline SA-187 & ST59 & $A B C$ & Patient & ФМuзА & 24.0 & $4 I .1$ & 0.1 & 2.0 & 82 & 1.4 \\
\hline SA-189 & ST59 & $A$ & Dairy & ФМuЗА & 18.0 & 33.2 & 0.2 & 3.2 & 106 & 1.4 \\
\hline SA-2II & ST6 & $A C$ & Dairy & ФSa3ms & 16.1 & 34.9 & II.I & 30 & 1,047 & 9.8 \\
\hline SA-217 & STI5 & A & Dairy & ФSa3ms & 14.2 & 33.1 & 12 & 33.5 & 1,109 & 14.1 \\
\hline SA-227 & ST59 & $A B$ & Patient & ФМu3А & 22.0 & 39.0 & 0.2 & 3.5 & 136 & I.I \\
\hline SA-230 & ST5 & A & Patient & ФМu3А & 17.9 & 33.5 & 1.3 & 7.1 & 238 & 2.7 \\
\hline SA-239 & ST6 & A & Meat & ФSa3ms & 19.2 & 36.7 & 0.3 & 3.7 & 136 & 1.2 \\
\hline SA-240 & STI & A & Meat & $\Phi S a 3 m s$ & 19.1 & 36.8 & 1.2 & 6.7 & 247 & 1.4 \\
\hline SA-253 & STI & $A C$ & Dairy & ФSa3ms & 20.0 & 35.6 & 0.4 & 7.0 & 249 & 2.3 \\
\hline SA-254 & STI & $A C$ & Dairy & ФSa3ms & 19.0 & 32.0 & 2.9 & 9.2 & 294 & 6.8 \\
\hline SA-255 & STI & $A C$ & Dairy & $\Phi S a 3 m s$ & 18.8 & 34.1 & 1.2 & 8.1 & 276 & 2.5 \\
\hline SA-256 & STI & $A C$ & Meat & ФSa3ms & 16.0 & 33.2 & 0.5 & 5.2 & 173 & 2.6 \\
\hline SA-262 & ST5 & $A C$ & Patient & ФМu3А & 15.0 & 32.9 & 1.3 & 5.4 & 178 & 1.9 \\
\hline SA-265 & STI & A & Meat & $\Phi S a 3 m s$ & 11.2 & 26.6 & 0.4 & 4.5 & 120 & 2.4 \\
\hline SA-282 & STI & $A B$ & Dairy & ФSa3ms & 9.8 & 25.3 & 3.1 & 8.9 & 225 & 3.5 \\
\hline SA-283 & STI & $A B$ & Dairy & ФSa3ms & 11.0 & 26.1 & 2.0 & 7.8 & 204 & 2.8 \\
\hline SA-284 & STI & $A B$ & Dairy & $\Phi S a 3 m s$ & 8.8 & 21.1 & 1.7 & 6.1 & 129 & 3.1 \\
\hline SA-335 & STI & A & Meat & ФSa3ms & 18.0 & 38.0 & 3.9 & 10.1 & 384 & 2.1 \\
\hline SA-337 & ST239 & A & Patient & ФМu3А & 22.3 & 39.2 & 1.1 & 5.1 & 200 & 3.1 \\
\hline SA-340 & ST239 & A & Patient & ФМu3А & 29.9 & 41.0 & 7.2 & 21.4 & 877 & 10.1 \\
\hline SA-34I & ST239 & A & Patient & $\begin{array}{l}\text { ФMu3A } \\
\text { ФSa3ms }\end{array}$ & 26.7 & 42.1 & 4.1 & 18.1 & 762 & 6.9 \\
\hline SA-346 & STI & A & Meat & $\Phi S \mathrm{a} 3 \mathrm{~ms}$ & 16.7 & 35.9 & 1.2 & 6.1 & 219 & 1.8 \\
\hline Mean & & & & & 18.26 & 34.37 & 2.37 & 8.74 & 305 & 3.64 \\
\hline SD & & & & & 5.26 & 5.12 & 3.06 & 7.70 & 281 & 3.17 \\
\hline Maximum & & & & & 31.1 & 43.0 & 12.0 & 33.5 & 1,109 & 14.1 \\
\hline Minimum & & & & & 8.8 & 21.1 & 0.1 & 2.0 & 36 & 1.0 \\
\hline
\end{tabular}

Abbreviations: CFU, colony-forming unit; SE, staphylococcal enterotoxin; SEA, staphylococcal enterotoxin A; SFP, staphylococcal food poisoning; ST, sequence type. 
(3 isolates), ST5 (2 isolates), ST188 (2 isolates) and ST15 (1 isolate). The genetic typing results demonstrated a predominant sea-positive ST1 lineage. PFGE also proved a similar cluster around the ST1 lineage. Especially, the only one outbreak-related isolate also belonged to ST1 (Figure 1 and Table 2).

The values of bacterial cell counts after $24 \mathrm{~h}$ of incubation showed limited variation, most focusing on $29-39 \times 10^{8} \mathrm{CFU} /$ $\mathrm{mL}$. After $6 \mathrm{~h}$ of incubation, on the average, bacterial cell counts accounted for $53 \%(18.26 / 34.37)$ of the maximal cell counts of $24 \mathrm{~h}$ of incubation (Table 2).

The amount of SEA after $24 \mathrm{~h}$ of incubation ranged from 1.1 to $33.5 \mathrm{ng} / 10^{8} \mathrm{CFU}$, with an average of 8.74 and most values at lower part of the range (Table 2 and Figure 2A). The amount of SEA per hour in the log growth phase ranged from 0.1 to
$12.0 \mathrm{ng} / 10^{8} \mathrm{CFU}$, with an average of 2.37 and most values also at lower part of the range (Table 2 and Figure 2A). Upon comparing the amount of SEA after $24 \mathrm{~h}$ of incubation with the amount of SEA of the $2 \mathrm{~h} \log$ growth phase (amount of SEA per hour [2.37] $\times 2)$, it was found that $54.2 \%(4.74 / 8.74)$ of SEA was produced in the $\log$ growth phase. This value was very close to the proportion (53\%) of bacterial cell counts in the $\log$ growth phase. Two linear regressions illustrated that both the transcriptional level of sea mRNA and the amount of SEA in the log growth phase correlated well with the 24-h amount of SEA. When arbitrarily setting the 24-h amount of SEA that was over the median value of the amount of SEA range as a cutoff value for high SEA production, four isolates, namely, SA-212, SA-217, SA-340 and SA-341, were categorized to be of high SEA production (Table 2).

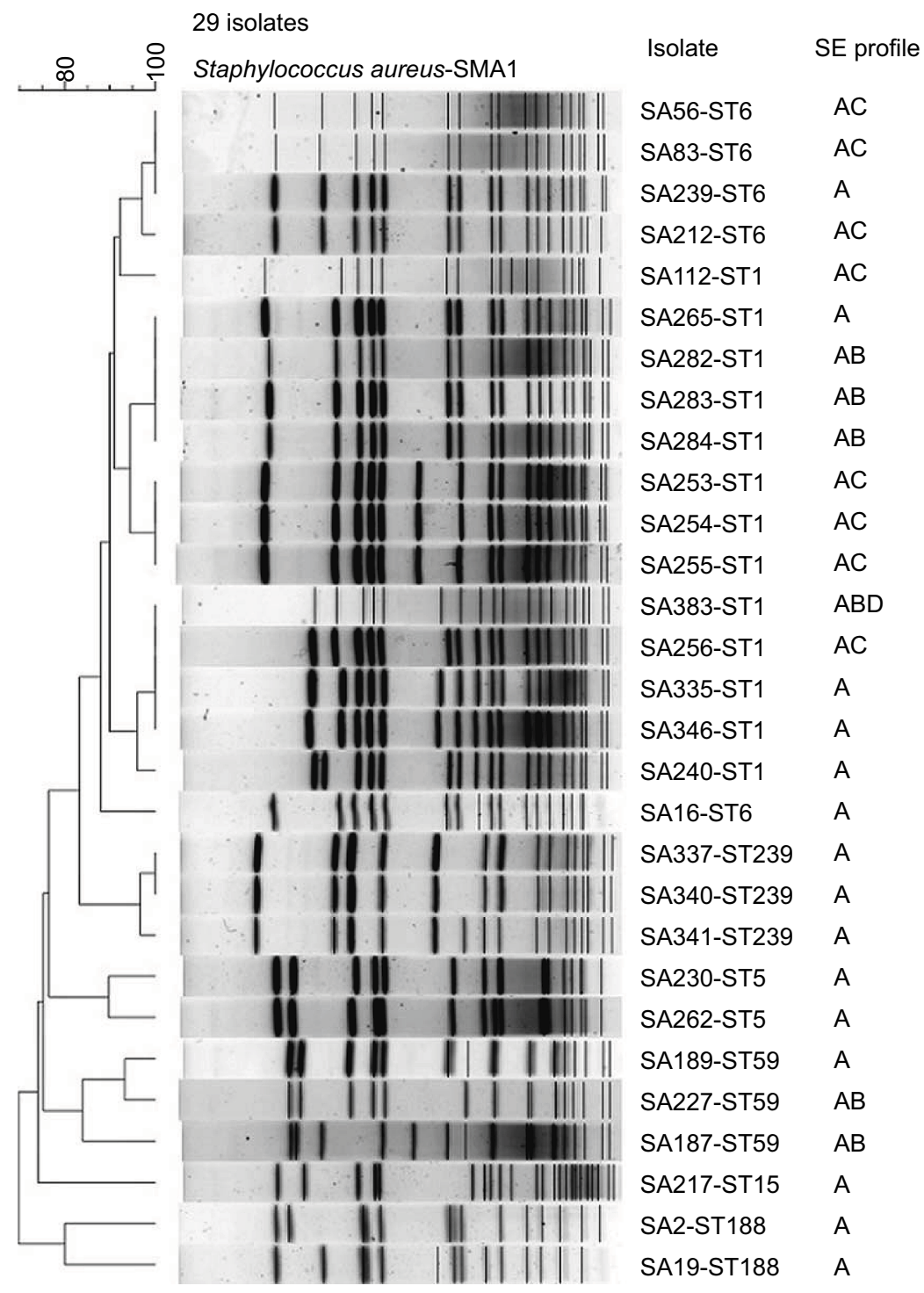

Figure I PFGE, MLST and SE profiles of 29 sea-positive Staphylococcus aureus isolates.

Abbreviations: MLST, multilocus sequence typing; PFGE, pulsed-field gel electrophoresis; SE, sequence type. 
As a measure indicating the production speed of SEA, the amount of SEA per hour in the log growth phase correlated well with the concentration of SEA at $24 \mathrm{~h}$ (Figure 2A). Similar correlation existed with the SEA expression level in the $\log$ growth phase and the amount of SEA at $24 \mathrm{~h}$ (Figure 2B). Upon integrating the bacterial cell counts, the amount of SEA in $10^{8} \mathrm{CFU}$ at $24 \mathrm{~h}$ and total amount of SEA at $24 \mathrm{~h}$, we could see that the total amount of SEA (y axis in Figure 2C and D) was determined largely by the amount of SEA in $10^{8} \mathrm{CFU}$ at $24 \mathrm{~h}$ (x axis in Figure 2C) and almost no apparent correlation with the bacterial cell counts ( $\mathrm{x}$ axis in Figure 2D).

As to types of phages that carry the sea gene, seven isolates carried the $\Phi \mathrm{Mu} 3 \mathrm{~A}$ phage and 22 isolates carried the $\Phi S a 3 \mathrm{~ms}$ phage (Table 2). It is important to note that the isolates from patients all carried the $\Phi \mathrm{Mu} 3 \mathrm{~A}$ phage and 21 of the 22 isolates from environmental sources carried the $\Phi S a 3 m s$ phage. This phenomenon generated a distinct boundary of phage type between two types of isolation sources.

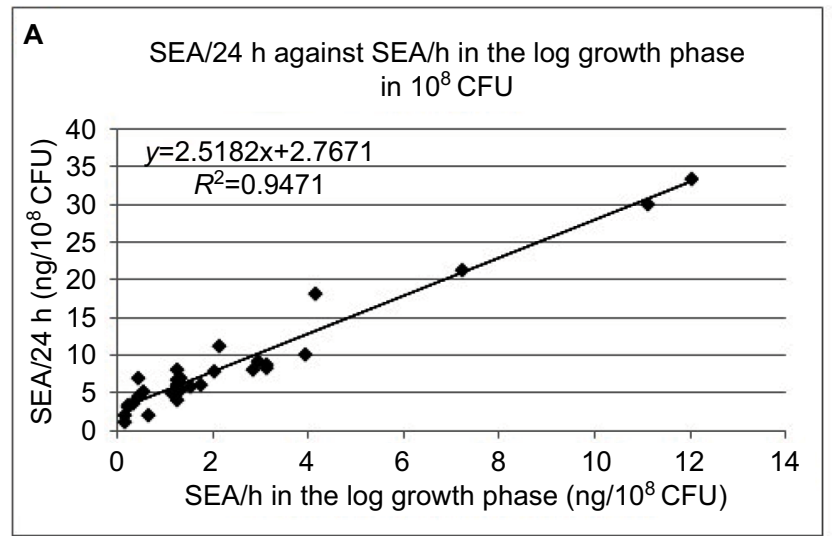

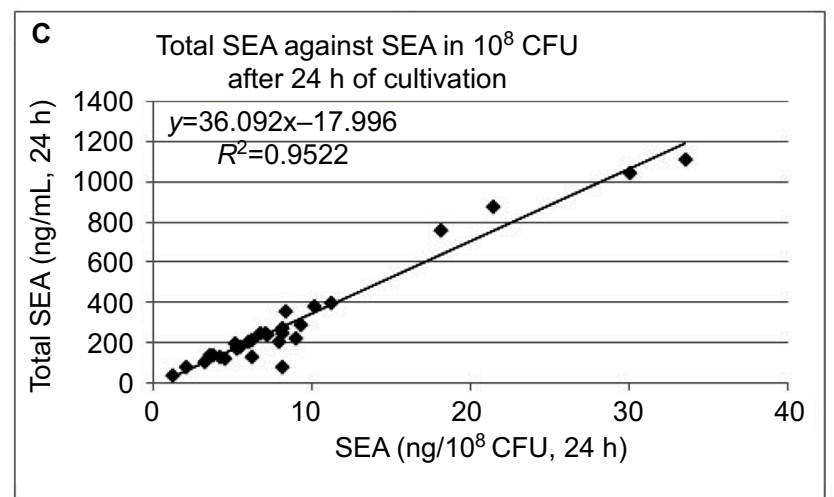

\section{Discussion}

The present study on the SEA production capacity of wild sea-positive $S$. aureus isolates yielded the following findings: although all isolates produced SEA at varied levels, isolates with high production capacity accounted for a small proportion of all isolates; production speed in the log growth phase decided the final SEA concentration, which further decided the total amount of SEA; transcriptional level of sea mRNA in the log growth phase could also well reflect the SEA production capacity; and there was an apparent boundary of phage types between isolates from clinical samples and isolates from the environment.

As shown by PFGE and MLST distribution, wild seapositive $S$. aureus isolates were found to focus on limited lineages genetically. Isolates of ST1 $(n=13)$ and ST6 $(n=5)$ accounted for most of the environmental isolates $(82 \%$, 18/22) (Figure 1 and Table 2). ST6 was previously reported to be the most dominant clone in China. ${ }^{18}$ ST5 and ST188 are also among the most found STs in SE-producing strains
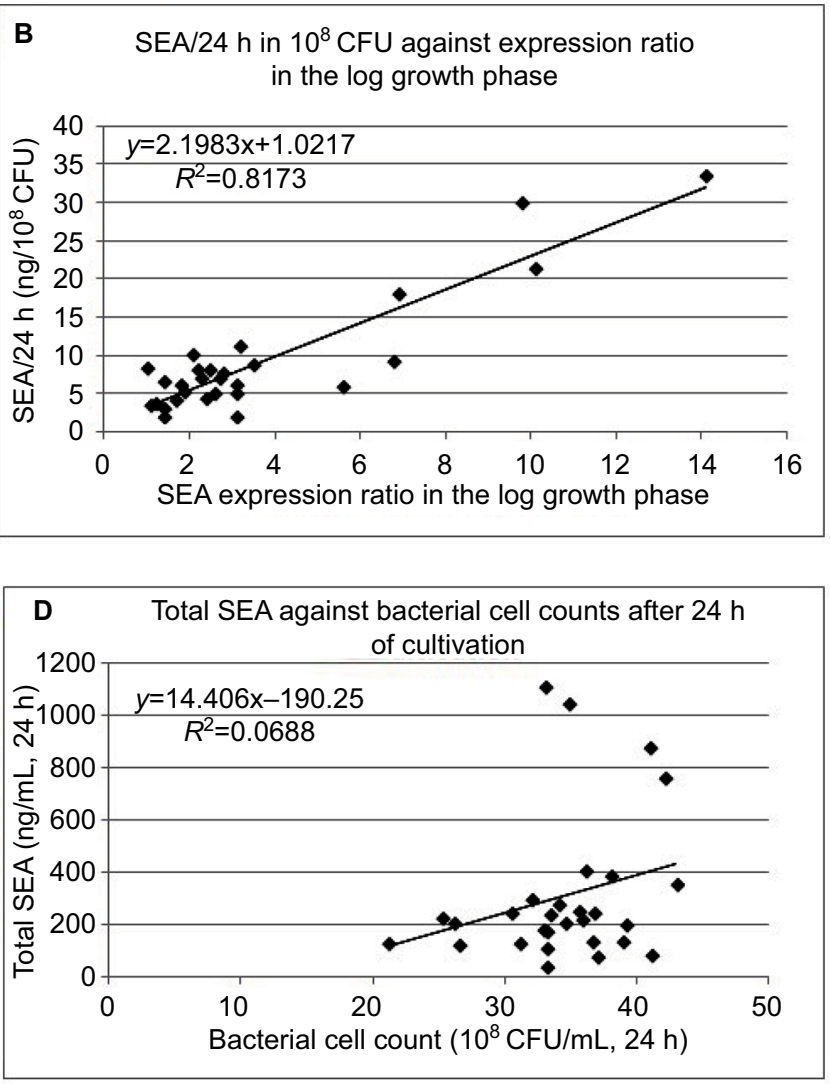

Figure 2 Relationship between SEA production after $24 \mathrm{~h}$ of incubation and per hour production in $10^{8} \mathrm{CFU}(\mathbf{A})$, and relevant expression ratio in the log growth phase (B) as well as after $24 \mathrm{~h}$ of incubation relationship between total amount of SEA and amount of SEA in $10^{8} \mathrm{CFU}$ (C), and relevant bacterial cell counts (D). (C) and (D show that total amount of SEA is mainly based on the amount of SEA in $10^{8} \mathrm{CFU}$, not the relatively fixed bacterial cell counts.

Abbreviations: CFU, colony-forming unit; SEA, staphylococcal enterotoxin A. 
both from foodborne cases and environmental sources. ${ }^{19,20}$ However, the remarkably large proportion of ST1 isolates in this study indicates a clustering trend in such strains. Regarding the hospital isolates in this study, ST239, ST5 and ST59 were most found STs.

This study proved that after $24 \mathrm{~h}$ of incubation all wild sea-positive $S$. aureus isolates could produce SEA at varied levels of amount. Several previous studies were performed concerning the influential factors such as temperature, prophage induction and $\mathrm{pH} \cdot{ }^{11,17}$ The results of these studies varied greatly due to such different influential factors on SEA production. Under favorable cultivation conditions at $37^{\circ} \mathrm{C}$ for $24 \mathrm{~h}$, it has been observed that $50-300 \mathrm{ng} / \mathrm{mL}$ of SEA is reached, ${ }^{11}$ and another report showed that $\sim 608-739 \mathrm{ng} / \mathrm{mL}$ has been detected on pork sausage, ${ }^{21}$ which is very close to the results of this study (average: $305 \mathrm{ng} / \mathrm{mL}$; range: $362-1,109 \mathrm{ng} / \mathrm{mL}$ ) after $24 \mathrm{~h}$ of incubation. In this study, the amount of SEA produced after $24 \mathrm{~h}$ of incubation by four highest SEA-producing isolates, namely, SA-212, SA-217, SA-340 and SA-341, was 10 times that produced by four lowest SEA-producing isolates, namely, SA-2, SA-19, SA-187 and SA-189. This gap was much smaller than a reported one that was $4 \log$ units and with a range of 2-10,378 ng/mL. ${ }^{17}$ Moreover, even without induction, substantial SEA could be detected in all isolates after $24 \mathrm{~h}$ of incubation. As a whole, the isolates with high production capacity accounted for a small proportion of all isolates (Table 2 and Figure 2). Especially, although SA-148 from an outbreak of 52 cases with a distinctive SE pattern of three SE genes, sea, seb and sed, did not produce very high amount of SEA, it still caused a serious foodborne outbreak probably due to its SED production. This proves the previous report that SEA along with SED is more prone to cause foodborne outbreaks. ${ }^{22}$ Taken into consideration the SEA production levels and genetic distribution, differential SEA production capacity existed among isolates of different genetic types. Most of the ST59 and ST188 isolates had low production capacity which could only be vaguely detected at the early incubation period and could only be safely proved toward the end of extended time of incubation.

We demonstrated that more than half $(54.2 \%, 4.74 / 8.74)$ of SEA was produced toward the end of the log growth phase, which was highly proportional to the bacterial cell count during the same period (Table 2). This phenomenon suggests that SEA production is substantially proportional to cell growth. However, in food where $S$. aureus grows much more slowly compared with growing under optimal experimental conditions, SEA production lasts for days. ${ }^{23}$ Both the transcriptional level of sea mRNA and the amount of SEA in the log growth phase correlated well with the 24-h amount of SEA, indicating that the high SEA-producing isolates began to express and produce SEA at the early phase of growth. The production speed in the log growth phase would decide the final SEA concentration and the total amount of SEA.

Here, we gained an interesting finding that the distinctive distribution of types of sea-carrying phages existed between isolates from environmental sources and those from clinical sources. Twenty-one of the 22 isolates from environmental sources carried the $\Phi S \mathrm{Sa} \mathrm{ms}$ phage, whereas seven from hospital sources all carried the $\Phi \mathrm{Mu} 3 \mathrm{~A}$ phage. Moreover, one hospital-originated SA-341 carried both. Among over 80 phages found in $S$. aureus, only five types harbor sea gene, which can be typed into integrase group $\mathrm{Sa}$, serogroup $\mathrm{Fa} /$ $\mathrm{Fb}$ and holigroup $255 \mathrm{a} / 255 \mathrm{~b} .{ }^{6}$ However, these typing methods overlap results between two distinct sea structures. In this study, we used the highly varied region of the end of phage tail gene and clearly differentiated two structurally different phages. More important, the method could generate a distinct boundary between environmental strains and hospital strains. As to the SEA production capacity, SA-212 and SA-217 with ФSa3ms and SA-340 and SA-341 with ФMu3A had high SEA-producing capacity, indicating that both phages had the ability to produce large amounts of SEA, although only in a few strains (Table 2).

\section{Conclusion}

The present study exhibits varied SEA production capacity of the wild sea-positive $S$. aureus strains in terms of SEA concentration and total amount of SEA after $24 \mathrm{~h}$ of incubation, as well as production speed and transcriptional level in the log growth phase. We also identified a distinctive boundary of phage types between strains from clinical samples and the environment.

\section{Acknowledgments}

This study was supported by the Natural Science Foundation of Ningbo (no. 2013A610246 and 2017A610273) and Wenzhou Science and Technology Project (Y20170148). This study also made use of the Multi Locus Sequence Typing website (http://www.mlst.net) at Imperial College London developed by David Aanensen and funded by the Wellcome Trust.

\section{Disclosure}

The authors report no conflicts of interest in this work. 


\section{References}

1. Eurosurveillance Editorial Team. The European Union summary report on trends and sources of zoonoses, zoonotic agents and food-borne outbreaks in 2011 has been published. Euro Surveill. 2013;18(15):20449.

2. Dinges MM, Orwin PM, Schlievert PM. Exotoxins of Staphylococcus aureus. Clin Microbiol Rev. 2000;13(1):16-34.

3. Omoe K, Ishikawa M, Shimoda Y, Hu DL, Ueda S, Shinagawa K. Detection of seg, seh, and sei genes in Staphylococcus aureus isolates and determination of the enterotoxin productivities of $S$. aureus isolates harboring seg, seh, or sei genes. J Clin Microbiol. 2002;40(3):857-862.

4. Kerouanton A, Hennekinne JA, Letertre C, et al. Characterization of Staphylococcus aureus strains associated with food poisoning outbreaks in France. Int J Food Microbiol. 2007;115(3):369-375.

5. Schelin J, Wallin-Carlquist N, Cohn MT, Lindqvist R, Barker GC, Radstrom P. The formation of Staphylococcus aureus enterotoxin in food environments and advances in risk assessment. Virulence. 2011;2(6):580-592.

6. Goerke C, Pantucek R, Holtfreter S, et al. Diversity of prophages in dominant Staphylococcus aureus clonal lineages. J Bacteriol. 2009;191(11):3462-3468.

7. Ikeda T, Tamate N, Yamaguchi K, Makino S. Mass outbreak of food poisoning disease caused by small amounts of staphylococcal enterotoxins A and H. Appl Environ Microbiol. 2005;71(5):2793-2795.

8. Asao T, Kumeda Y, Kawai T, et al. An extensive outbreak of staphylococcal food poisoning due to low-fat milk in Japan: estimation of enterotoxin A in the incriminated milk and powdered skim milk. Epidemiol Infect. 2003;130(1):33-40.

9. Varshney AK, Mediavilla JR, Robiou N, et al. Diverse enterotoxin gene profiles among clonal complexes of Staphylococcus aureus isolates from the Bronx, New York. Appl Environ Microbiol. 2009;75(21): 6839-6849.

10. Bianchi DM, Gallina S, Bellio A, Chiesa F, Civera T, Decastelli L. Enterotoxin gene profiles of Staphylococcus aureus isolated from milk and dairy products in Italy. Lett Appl Microbiol. 2014;58(2): 190-196.

11. Tsutsuura S, Shimamura Y, Murata M. Temperature dependence of the production of staphylococcal enterotoxin A by Staphylococcus aureus. Biosci Biotechnol Biochem. 2013;77(1):30-37.
12. Maes N, Magdalena J, Rottiers S, De Gheldre Y, Struelens MJ. Evaluation of a triplex PCR assay to discriminate Staphylococcus aureus from coagulase-negative Staphylococci and determine methicillin resistance from blood cultures. J Clin Microbiol. 2002;40(4):1514-1517.

13. Rosec JP, Gigaud O. Staphylococcal enterotoxin genes of classical and new types detected by PCR in France. Int J Food Microbiol. 2002;77(1-2):61-70.

14. Mark Enright. Multilocus Sequence Typing (MLST) of Staphylococcus aureus. the laboratory of Brian Spratt, Imperial College London. Available from: http://saureus.mlst.net/. Accessed August 1, 2017.

15. Foodborne and Diarrheal Diseases Branch DoBaMD; National Center for Infectious Diseases, Centers for Disease Control and Prevention. Standardized Molecular Subtyping of Foodborne Bacterial Pathogens by Pulsed-Field Gel Electrophoresis: A Training Manual. Atlanta: Centers for Disease Control and Prevention; 2000.

16. Pfaffl MW. A new mathematical model for relative quantification in real-time RT-PCR. Nucleic Acids Res. 2001;29(9):e45.

17. Cao R, Zeaki N, Wallin-Carlquist N, Skandamis PN, Schelin J, Radstrom P. Elevated enterotoxin A expression and formation in Staphylococcus aureus and its association with prophage induction. Appl Environ Microbiol. 2012;78(14):4942-4948.

18. Yan X, Wang B, Tao X, et al. Characterization of Staphylococcus aureus strains associated with food poisoning in Shenzhen, China. Appl Environ Microbiol. 2012;78(18):6637-6642.

19. Chang Y, Gao H, Zhu Z, et al. High prevalence and properties of enterotoxin-producing Staphylococcus aureus ST5 strains of food sources in China. Foodborne Pathog Dis. 2016;13(7):386-390.

20. Song Q, Zhu Z, Chang Y, Shen X, Gao H, Yang Y. Prevalence and characteristics of enterotoxin B-producing Staphylococcus aureus isolated from food sources: a particular cluster of ST188 strains was identified. J Food Sci. 2016;81(3):M715-M718.

21. Zeaki N, Cao R, Skandamis PN, Radstrom P, Schelin J. Assessment of high and low enterotoxin A producing Staphylococcus aureus strains on pork sausage. Int J Food Microbiol. 2014;18(2-183):44-50.

22. Argudin MA, Mendoza MC, Rodicio MR. Food poisoning and Staphylococcus aureus enterotoxins. Toxins (Basel). 2010;2(7):1751-1773.

23. Wallin-Carlquist N, Marta D, Borch E, Radstrom P. Prolonged expression and production of Staphylococcus aureus enterotoxin A in processed pork meat. Int J Food Microbiol. 2010;141(Suppl 1):S69-S74.
Infection and Drug Resistance

\section{Publish your work in this journal}

Infection and Drug Resistance is an international, peer-reviewed openaccess journal that focuses on the optimal treatment of infection (bacterial, fungal and viral) and the development and institution of preventive strategies to minimize the development and spread of resistance. The journal is specifically concerned with the epidemiology of antibiotic

\section{Dovepress}

resistance and the mechanisms of resistance development and diffusion in both hospitals and the community. The manuscript management system is completely online and includes a very quick and fair peerreview system, which is all easy to use. Visit http://www.dovepress.com/ testimonials.php to read real quotes from published authors. 